\title{
Iatrogenic Cushing's Syndrome Caused by Topical Corticosteroid Application and Its Life Threatening Complications
}

\author{
Maryam Razzaghy Azar, ${ }^{1,2}$ Asieh Mosalla Nejad, ${ }^{3}$ Ensieh Nasli Esfahani, ${ }^{2}$ and Mona \\ Noubakhsh ${ }^{1}$ \\ ${ }_{1}^{1}$ Aliasghar Hospital, Iran University of Medical Sciences, Tehran, IR Iran \\ ${ }^{2}$ Metabolic Disorders Research Center, Endocrinology and Metabolism Molecular-Cellular Sciences Institute, Tehran University of Medical Sciences, Tehran, IR Iran \\ ${ }^{3}$ Imam Hossein Medical Center, Shahid Beheshti University of Medical Sciences, Tehran, IR Iran \\ *Corresponding author: Maryam Razzaghy Azar, Aliasghar Hospital, Iran University of Medical Sciences, Tehran, IR Iran. E-mail: mrazar_md@yahoo.com
}

Received 2015 November 3; Accepted 2015 November 15.

\begin{abstract}
Introduction: The use of topical corticosteroids in children and adults, especially in covered areas and for a prolonged duration, may result in Cushing's syndrome and suppression of the hypothalamic-pituitary-adrenal axis.

Case Presentation: The present report describes the cases of three children and a 25-year-old man who presented with clinical features of Cushing's syndrome and adrenal insufficiency following prolonged use of clobetasol cream. Two of the children continued with hypertension even after discontinuation of clobetasol, and were treated with angiotensin-converting enzyme inhibitors. One of these two children had developed acute renal failure, hypertensive encephalopathy, and permanent visual loss prior to admission.

Conclusions: Whenever a cushingoid appearance is accompanied by adrenal insufficiency, the exogenous use of steroids, especially topical creams, should be explored. Hypertension may persist even after cessation of use and may result in life threatening complications.
\end{abstract}

Keywords: Cushing's Syndrome, Diaper Rash, Clobetasol, Adrenal Insufficiency, Hypothalamic-Pituitary-Adrenal Axis

\section{Introduction}

Topical corticosteroids are widely used to treat various skin and inflammatory disorders. However, topical corticosteroid use may lead to several adverse effects. Absorption through the skin may lead to Cushing's syndrome with suppression of the hypothalamic-pituitaryadrenal axis (1). Decani et al. (2) reported on the cases of five patients with systemic side effects following the use of topical corticosteroids, whereas 43 cases with exogenous Cushing's syndrome over 35 years, two of whom died from severe cytomegalovirus infection, have been reviewed and reported by Tempark et al. (3). The use of clobetasol propionate, a potent corticosteroid, has not been adequately assessed in children, and is therefore not recommended in those aged under 12 years (3).

\section{Case Presentation}

Herein, the cases of three children and a 25-year-old man with a history of topical steroid usage (clobetasol propionate) for diaper rash and dermatitis, respectively, are described. All four cases developed Cushing's syn- drome, with life threatening consequences in one case. After a complete physical examination, the children's height and weight were plotted on CDC 2000 US curves. Standard deviation scores were calculated as patient height minus 50th percentile height/standard deviation for age and sex. Cortisol and adrenocorticotropic hormone (ACTH) were measured by electrochemiluminescence immunoassay (Cobas e411, Roche Diagnostics, Mannheim, Germany).

\subsection{Case 1}

An 11-month-old boy was referred to the endocrine clinic because of irritability and obesity. He was born through normal vaginal delivery at 38 weeks gestation, with a birth weight of 3,250 kg from healthy, unrelated parents. He had an 8-month history of diaper rash and his mother had applied clobetasol propionate ointment $0.05 \%, 6$ - 7 times a day, for 4 months, and continued with $3-4$ daily applications for a further 4 months. On physical examination, he had a blood pressure of

Copyright ( 2015, Iranian Society of Pediatrics. This is an open-access article distributed under the terms of the Creative Commons Attribution-NonCommercial 4.0 International License (http://creativecommons.org/licenses/by-nc/4.0/) which permits copy and redistribute the material just in noncommercial usages, provided the original work is properly cited. 
$170 / 100 \mathrm{mmHg}$, a pulse rate of 90 beats/min, body temperature of $37^{\circ} \mathrm{C}$, and a respiratory rate of 25 breaths/ min. A cushingoid appearance, moon face, telangiectasia on the cheeks, hypertrichosis and several ecchymotic skin lesions were found on the face and limbs (Figure 1). He had a diaper rash with erythematous papules, suggestive of candidiasis. His body weight and height were $8.6 \mathrm{~kg}$ (between 10th and 25th percentile in the CDC 2000 growth curves) and $64 \mathrm{~cm}$ (under 3rd percentile, -4 standard deviation scores), respectively, and he had a head circumference of $45 \mathrm{~cm}$ (between 25th and 50th percentile).

Blood tests revealed low levels of cortisol and ACTH in the 08:00 AM (Table 1). Other laboratory evaluations were as follows: hemoglobin, $12.4 \mathrm{~g} / \mathrm{dL}$; white blood cell, $12,000 / \mathrm{mm} 3$; serum creatinine, $0.5 \mathrm{mg} / \mathrm{dL}$; serum sodium, $136 \mathrm{mEq} / \mathrm{L}$; serum potassium, $4.3 \mathrm{mEq} / \mathrm{L}$; and fasting plasma glucose, $114 \mathrm{mg} / \mathrm{dL}$ (returned to normal on follow-up). The lipid profile showed higher than normal cholesterol (241 mg/dL) and low-density lipoprotein (164 $\mathrm{mg} / \mathrm{dL}$ ) levels for age and sex, both of which returned to normal on follow-up. Triglyceride and high-density lipoprotein were both normal and 24-h urine-free cortisol was $10 \mathrm{~g}$ (normal range, 10 - 100). Serum aldosterone was $114 \mathrm{pg} / \mathrm{mL}(25-313)$ and renin was elevated (> 500 $\mathrm{ng} / \mathrm{mL}$ ). Echocardiogram, retinal examination, and Doppler sonography of the kidneys were normal. Sonography of the adrenal glands and computerized tomography of the abdomen and pelvis were normal, without any space-occupying lesions, although mild fatty liver was reported.

Topical steroid application was stopped, and the patient was administered a physiological dose of hydrocortisone and gradually tapered. Topical Clotrimazole was applied for skin lesions and a stress dose of hydrocortisone was suggested during illness, fever, and surgery to prevent adrenal crisis. Hypertension was controlled with intravenous labetalol, and then changed to enalapril. Figure 2 reveals the patient's face after 4 months of discontinuation of hydrocortisone.

\subsection{Case 2}

The patient was a 4-month-old boy referred due to a cushingoid face (Figure 3). He was born full term from unrelated, healthy parents by cesarean delivery. On physical examination, his weight and height were normal, at $6.650 \mathrm{~kg}$ (between 25th and 50th percentile) and $63 \mathrm{~cm}$ (on 50th percentile), although cushingoid features were noticed. The mother had applied clobetasol cream on the diaper area since birth until 3 months and 1 week. Despite clinical manifestations of Cushing's syndrome, serum cortisol and ACTH were low (Table 1). Sonography of adrenal glands was normal. Arterial blood gas, cell blood count, 3-hour fasting plasma glucose, and the biochemical profile were all normal. The orders for stress were suggested for him and hydrocortisone was not administered.

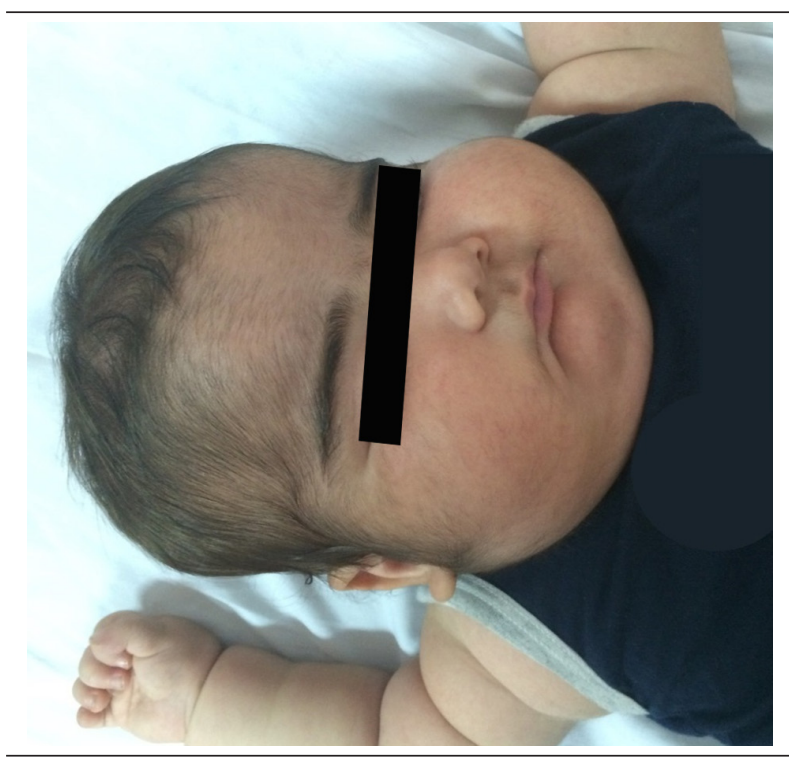

Figure 1. An 11-Month-Old Boy (Case 1) Presenting With a Moon Face Appearance and Telangiectasia on the Cheeks

\begin{tabular}{|c|c|c|}
\hline & Cortisol $(\mu \mathrm{g} / \mathrm{dL})$ & $\begin{array}{c}\text { Adrenocorticotropic } \\
\text { Hormone (pg/mL) }\end{array}$ \\
\hline \multicolumn{3}{|l|}{ Case 1} \\
\hline \multicolumn{3}{|l|}{ Age, mo } \\
\hline 11 & 0.72 & 1.5 \\
\hline \multicolumn{3}{|l|}{ Case 2} \\
\hline \multicolumn{3}{|l|}{ Age, mo } \\
\hline 4 & 3.3 & 18.7 \\
\hline \multicolumn{3}{|l|}{ Case 3} \\
\hline \multicolumn{3}{|l|}{ Age, y } \\
\hline 3.5 & 2.14 & 1.83 \\
\hline \multicolumn{3}{|l|}{ Case 4} \\
\hline \multicolumn{3}{|l|}{ Age, y } \\
\hline 25 & 0.5 & $<1$ \\
\hline Reference values & $5-16$ & $7.2-63$ \\
\hline
\end{tabular}

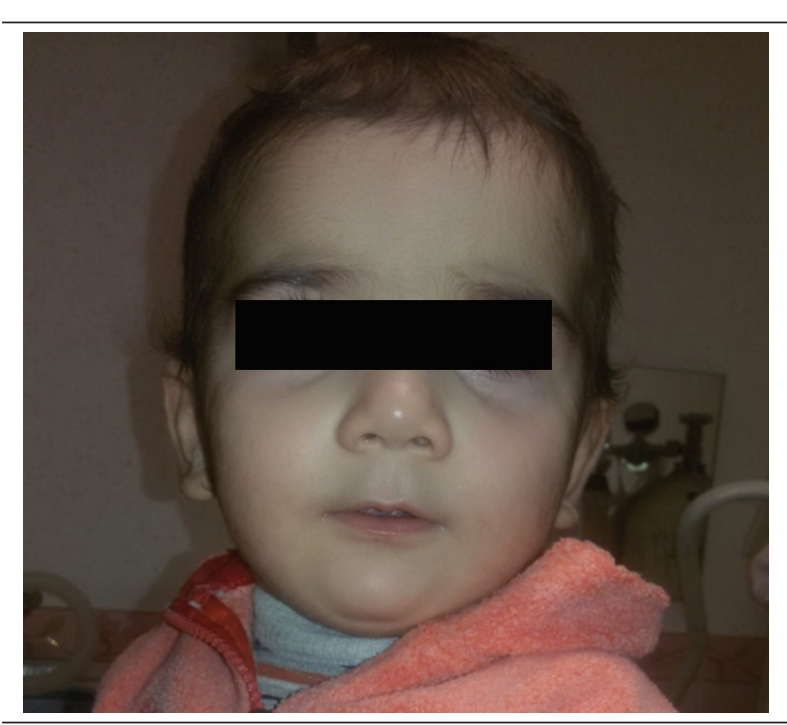

Figure 2. 4 Months After Hydrocortisone was Stopped (Case 1) 


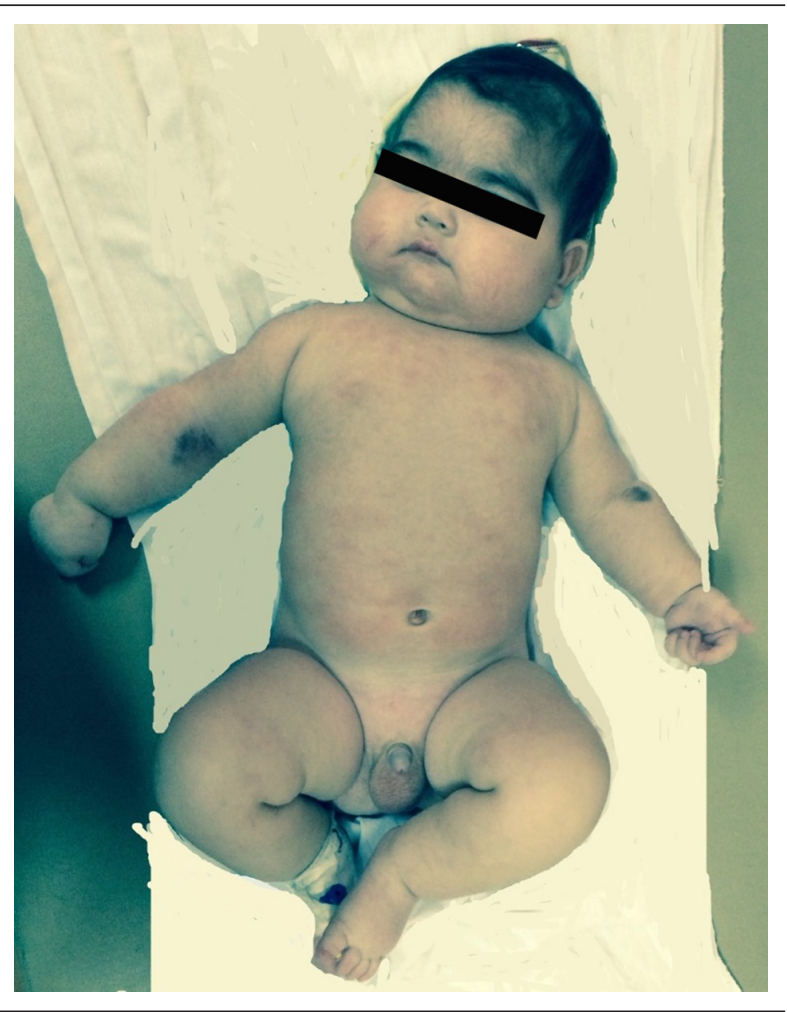

Figure 3. A 4-Month-Old Boy Referred Due to Cushingoid Face

\subsection{Case 3}

This patient was a 3.5-year-old boy with clinical features of Cushing's syndrome consisting of a round plethoric face, a buffalo hump, and abdominal obesity, which appeared at 2 years of age according to his medical report. He had a history of prolonged clobetasol use on the diaper area. After discontinuation of clobetasol, hydrocortisone had been started for adrenal insufficiency. Nevertheless, hypertension, commonly accompanying Cushing's syndrome, continued after clobetasol discontinuation. The child had presented with hypertensive encephalopathy, acute renal failure, and impaired vision, and therefore had been treated with angiotensin-converting enzyme inhibitors. Encephalopathy and renal failure had regressed, but the visual damage was permanent. During renal insufficiency, he had the history of serum sodium and potassium levels of $119 \mathrm{mEq} / \mathrm{L}$ and $2.8 \mathrm{mEq} / \mathrm{L}$, respectively, which later returned to normal. His laboratory test results are illustrated in Table 1 . A tapering and stress dose schedule was given to the parents.

\subsection{Case 4}

The patient was a 25-year-old man who had gained 9 $\mathrm{kg}$ in the past 2 years with associated facial fullness and plethora. He had a history of dry skin and had been treated with topical clobetasol ointment 3 times per week on his hands and face (Figure 4).

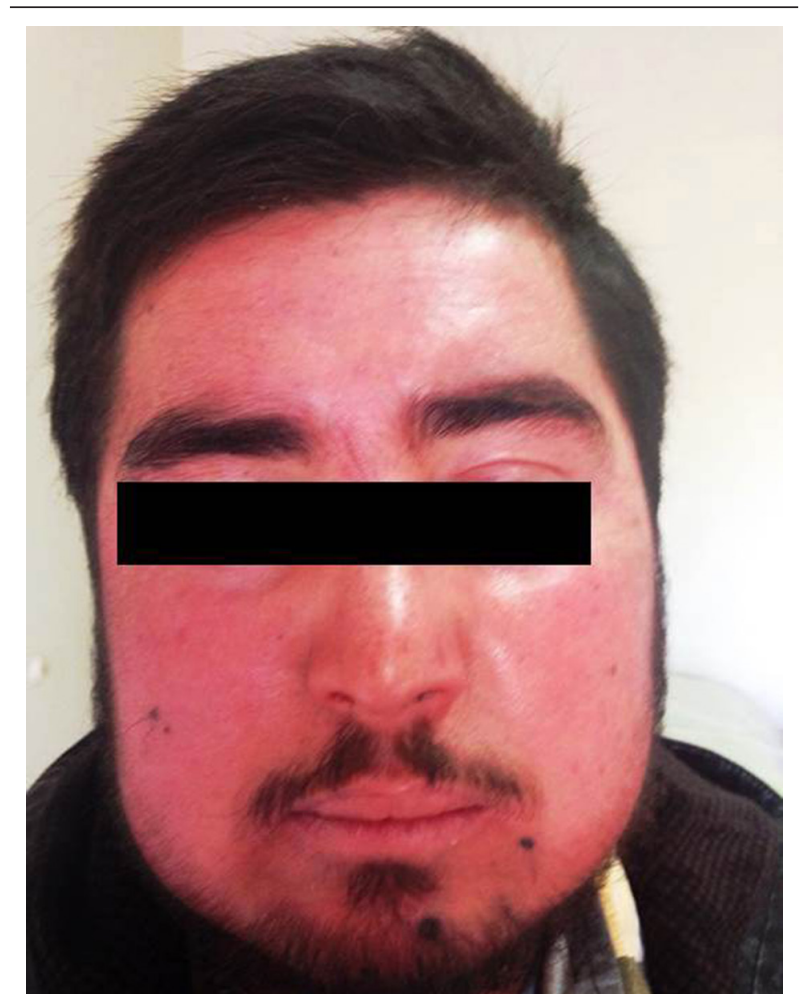

Figure 4. The Picture of Adult Patient

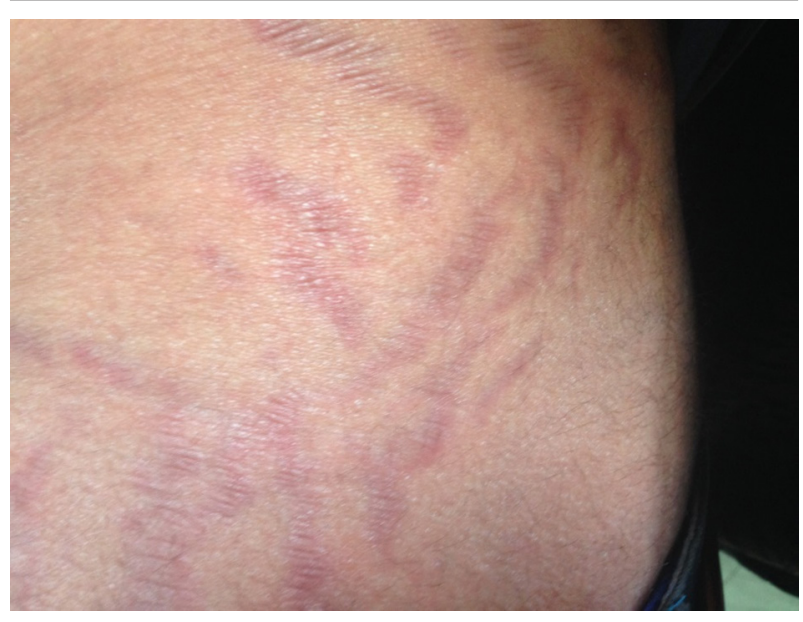

Figure 5. Patient's Abdomen Showing Striae (Case 5)

On physical examination, he had a cushingoid-appearance with a blood pressure of 143/95 $\mathrm{mmHg}$ and a pulse rate of 72 beats/min. His height and weight were $167 \mathrm{~cm}$ and $72.5 \mathrm{~kg}$, respectively. He had substantial supraclavicular and dorsocervical fat accumulation (Buffalo hump) and striae on the lower abdomen, arm, and upper thigh (Figure 5). Laboratory findings were as follows: serum sodium, $145 \mathrm{mEq} / \mathrm{L}$; serum potassium, $3.9 \mathrm{mEq} / \mathrm{L}$; fasting blood sugar, $92 \mathrm{mg} / \mathrm{dL}$; creatinine, $0.8 \mathrm{mg} / \mathrm{dL}$; and 24-hour urine-free cortisol, $2.8 \mu \mathrm{g}$. Thyroid function tests were normal. Prednisolone at a dose of $7.5 \mathrm{mg} /$ day, divided in 
two daily doses, was administered and tapered over 3 months. After a further 3 months, cortisol and ACTH levels returned to normal.

\section{Discussion}

The current report describes the cases of three children presenting with clinical features of Cushing's syndrome following prolonged treatment of a diaper rash with clobetasol and that of an adult patient presenting with similar features following clobetasol application on the face and hands. Topical steroids are systemically absorbed and may cause adverse side effects such as iatrogenic Cushing's syndrome and adrenal suppression due to inhibition of corticotropin-releasing hormone/ACTH secretion $(1,2)$. Cushing's syndrome has been reported in both children and adults following the prolonged use of potent corticosteroids as topical cream or oral solutions (26). Peppa et al. (7) reported that hypertension is less profound in exogenous, corticosteroid-induced Cushing's syndrome; nevertheless, in two of the cases herein, hypertension was profound and persisted even after corticosteroid discontinuation and was accompanied by adrenal insufficiency. In one patient, the side effects resulted in life threatening events, hypertensive encephalopathy, renal insufficiency with sodium and potassium wasting, and permanent visual loss. In case 1, aldosterone levels were normal but renin levels were high, indicating that aldosterone levels may have been normal at the expense of high renin levels, which may have also lead to high angiotensin (a potent vasopressor) levels, although this was not measured. Despite adrenal insufficiency and discontinuation of hydrocortisone, hypertension persisted; this is of particular importance in the treatment of pediatric patients for whom blood pressure measurement is difficult due to crying of the child. Clobetasol propionate is a potent steroid (600 - 1000 times more potent compared to hydrocortisone) and is claimed to have a low skin absorption, nevertheless, all of the patients herein used this drug. Even relatively low doses of this class of steroids ( $2 \mathrm{~g} /$ day for 2 weeks) have been associated with adrenal gland suppression. $(8,9)$ Highly vascular areas, such as the ear canals and areas under occlusion such as the diaper area, have been associated with enhanced systemic absorption $(8,9)$. Differences in individual sensitivity to corticosteroids should also be considered (2). In 1998, Huizenga et al. (10) described a polymorphism in the glucocorticoid receptor gene that was associated with increased receptor sensitivity. N363S mutation has also shown an increase in the therapeutic effect of glucocorticoids (2). Mucocutaneous infections are common during corticosteroid treatment, often occurring early in the therapy and likely being caused by immunosuppression $(10,11)$. Whenever a cushingoid appearance is accompanied by adrenal insufficiency, the exogenous use of steroids, especially topical creams, should be explored. Hypertension may persist even after cessation of use and may result in life threatening complications. The possible complications of long-term topical steroid applications should be appropriately indicated to the patients.

\section{Footnote}

Authors' Contribution:Maryam Razzaghy Azar wrote the medical report for case 2, as well as the methods, discussion and tables, and edited the manuscript. Asieh Mosalla Nejad wrote the draft manuscript and the medical report for case 1. Ensieh Nasli Esfahani wrote the medical report for case 4 . Mona Nourbakhsh wrote the medical report for case 3 . The patients were attended by the authors who wrote the medical reports.

\section{References}

1. Boscaro M, Barzon L, Fallo F, Sonino N. Cushing's syndrome. J Lan cet. 2001;357(9258):783-91. doi:10.1016/s0140-6736(00)04172-6.

2. Decani S, Federighi V, Baruzzi E, Sardella A, Lodi G. Iatrogenic Cushing's syndrome and topical steroid therapy: Case series and review of the literature. J Dermatolog Treat. 2014;25(6):495-500. doi:10.3109/09546634.2012.755252. [PubMed: 23210698]

3. Tempark T, Phatarakijnirund V, Chatproedprai S, Watcharasindhu S, Supornsilchai V, Wananukul S. Exogenous Cushing's syndrome due to topical corticosteroid application: case report and review literature. Endocrine. 2010;38(3):328-34. doi: 10.1007| s12020-010-9393-6. [PubMed:20972726]

4. Bulus AD, Andıran N, Kocak M. Cushing's syndrome: hidden risk in usage of topical corticosteroids. J Pediatr Endocrinol Metab. 2014;27(9-10):977-81. [PubMed: 24854522]

5. Rustowska A, Wilkowska A, Nowicki R. Iatrogenic Cushing syndrome due to topical glicocorticosteroid therapy. Dermatol Online J. 2013;4(4):503-5. doi: 10.7241/ourd.20134.129.

6. Ozdemir A, Bas VN. Iatrogenic Cushing's syndrome due to overuse of topical steroid in the diaper area. $J$ Trop Pediatr. 2014;60(5):404-6. doi: 10.1093/tropej/fmu036. [PubMed: 25016382]

7. Peppa M, Krania M, Raptis SA. Hypertension and other morbidities with Cushing's syndrome associated with corticosteroids: A review. Integrated blood pressure control. 2011;4:7. [PubMed: 21949634]

8. Nieman LK. Consequences of systemic absorption of topical glucocorticoids. J Am Acad Dermatol. 2011;65(1):250-2. doi: 10.1016/j. jaad.2010.12.037. [PubMed:21679844]

9. Semiz S, Balci YI, Ergin S, Candemir M, Polat A. Two cases of Cushing's syndrome due to overuse of topical steroid in the diaper area. Pediatr Dermatol. 2008;25(5):544-7. doi:10.1111/j.15251470.2008.00735.x. [PubMed:18950396]

10. Huizenga NA, Koper JW, De Lange P, Pols HA, Stolk RP, Burger H, et al. A polymorphism in the glucocorticoid receptor gene may be associated with and increased sensitivity to glucocorticoids in vivo. J Clin Endocrinol Metab. 1998;83(1):144-51. doi: 10.1210/ jcem.83.1.4490. [PubMed: 9435432]

11. Aucott JN. Glucocorticoids and infection. Endocrinol Metab Clin North Am.1994;23(3):655-70. [PubMed:7805661] 